\title{
Questes
}

\section{Gens de guerre en hiver : le cas des Écorcheurs durant l'hiver 1438-1439}

\section{Christophe Furon}

\section{(2) OpenEdition}

Journals

\section{Édition électronique}

URL : http://journals.openedition.org/questes/4374

DOI : 10.4000/questes.4374

ISSN : 2109-9472

\section{Éditeur}

Les Amis de Questes

\section{Édition imprimée}

Date de publication : 15 décembre 2016

Pagination : 85-118

ISSN : 2102-7188

\section{Référence électronique}

Christophe Furon, « Gens de guerre en hiver : le cas des Écorcheurs durant l'hiver 1438-1439 »,

Questes [En ligne], 34 | 2016, mis en ligne le 21 décembre 2016, consulté le 30 avril 2019. URL : http:// journals.openedition.org/questes/4374; DOI : 10.4000/questes.4374 


\title{
Gens de guerre en hiver : le cas des Écorcheurs durant l'hiver 1438-1439
}

\section{Christophe FURON}

\author{
Université Paris-Sorbonne
}

L'hiver médiéval ne marque pas un arrêt de l'activité guerrière. Philippe Contamine l'a souligné : sur 120 combats et batailles livrés aux $\mathrm{XIV}^{\mathrm{e}}$ et $\mathrm{XV}^{\mathrm{e}}$ siècles, 25 le furent de novembre à mars ${ }^{1}$ si l'on suit la définition météorologique de la saison hivernale ${ }^{2}$. Mais ce décompte laisse de côté les chevauchées, les prises d'assaut de places et les sièges qui constituent à l'époque l'essentiel de l'activité guerrière. À cela, il faut ajouter les actes de pillages et les boutements de feu qui accompagnent inévitablement toutes ces opérations, participant d'une guerre de harcèlement destinée à affaiblir moralement et économiquement l'adversaire ${ }^{3}$. En hiver, les gens de guerre ne restent donc pas inactifs et, lorsqu'ils ne sont pas engagés dans des armées régulières, ils doivent faire face aux problèmes de logement et d'approvisionnement. Cette saison marquée par de fortes contraintes climatiques pèse sur le quotidien d'hommes n'ayant généralement pour ressources que leurs seules armes.

\footnotetext{
${ }^{1}$ Philippe Contamine, La Guerre au Moyen Âge, Paris, PUF, 1980, p. 376.

${ }^{2}$ François Walter, Hiver. Histoire d'une saison, Paris, Payot, 2014, p. 33.

${ }^{3}$ Philippe Contamine, "L'impact de la guerre de Cent Ans en France sur le "plat pays" et sur la vie au village », dans Les Villageois face à la guerre (XIV ${ }^{e}-X V I I I^{e}$ siècle), Actes des XXII Journées Internationales d'Histoire de l'Abbaye de Flaran, dir. Christian Desplat, Toulouse, Presses universitaires du Mirail, 2002, p. 15-34; Michael Jucker, «Le butin de guerre au Moyen Âge. Aspects symboliques et économiques », Francia, vol. 36, 2009, p. 113-133 ; Franck Viltart, «Exploitiez la guerre par tous les moyens! Pillages et violences dans les campagnes militaires de Charles le Téméraire (1466-1476) », Revue du Nord, vol. 91, avril-juin 2009, p. 473490.
} 
Par conséquent, l'hiver représente a priori une période particulière pour les gens de guerre puisqu'ils doivent faire face aux difficultés météorologiques mais aussi matérielles dans un contexte de baisse d'activité.

Le cas des Écorcheurs durant l'hiver 1438-1439 peut aider à mieux cerner le degré de singularité que représente cette saison climatique pour des gens d'armes. Ce phénomène se développe après le traité d'Arras de 1435, qui marque la fin des hostilités entre Charles VII, roi de France, et Philippe le Bon, duc de Bourgogne. Même s'il reste à combattre l'ennemi anglais, beaucoup d'hommes d'armes se retrouvent au chômage et se livrent au pillage et au rançonnement des populations pour subvenir à leurs besoins :

Et tousjours faisoient de très grans maulx partout où ilz passoient. Et ne se tenoient point contens de prendre vivres, mais rançonnoient tous ceulx qu'ilz povoient attaindre, tant de paysans, comme de bestail et aultres biens ${ }^{4}$.

Les violences commises leur sont associées à tel point que les lettres de rémission usent de formules stéréotypées pour les décrire :

[Robert de Flocques] a eue grant charge de gens de guerre [...] lesquelz ont fait et commis meurtres, sacrileges, forcemens de femmes, boutemens de feux, pilleries, raenconnemens et autres plusieurs maulx qu'il ne sauroit nombrer ne speciffier $[\ldots]^{5}$.

Ces déprédations leur valent le nom d'Écorcheurs, emprunté au monde de la boucherie et qui traduit bien toute la cruauté dont les contemporains les affublent $^{6}$. Ce qualificatif est surtout utilisé par les sources

\footnotetext{
${ }^{4}$ Enguerran de Monstrelet, Chronique, éd. Louis Douët d'Arcq, t. V, Paris, Renouard, 1861, p. 317.

${ }^{5}$ Archives nationales (désormais AN), JJ 179, nº 49 (août 1448).

6 Sur les Écorcheurs, voir: Alexandre Tuetey, Les Écorcheurs sous Charles VII. Épisodes de l'histoire militaire de la France au $X V^{e}$ siècle d'après des documents inédits, Montbéliard, Henri Barbier, 1874, 2 vol. ; Joseph de Fréminville, Les 
bourguignonnes, qui soulignent souvent que leurs capitaines servent habituellement le roi de France, tandis que les régions germanophones les appellent plus volontiers Armagnacs ${ }^{7}$. Quel que soit le terme employé, il renvoie à l'archétype du criminel de guerre commettant pillages et violences sans nombre. Il vise également la responsabilité du roi de France: par leurs exactions, ces troupes remettent en cause l'ordre politique et moral dont il est le garant mais qu'il ne parvient pas à maintenir ${ }^{8}$.

Plusieurs indices tendent à montrer que, loin de s'estomper, le phénomène prend de l'ampleur durant l'hiver 1438-1439. Même s'il faut prendre leurs estimations d'effectifs avec précaution, les chroniqueurs, qui décrivent jusque-là de bandes de quelques milliers d'hommes au

Écorcheurs en Bourgogne (1435-1445). Étude sur les compagnies franches au $X V^{e}$ siècle, Dijon, 1887 ; Jean-Marie Cauchies, «Les "écorcheurs" en Hainaut (14371445) », Revue belge d'histoire militaire, vol. XX, n 5, mars 1974, p. 317-339; Valérie Toureille, «Pillage ou droit de prise. La question des Écorcheurs pendant la guerre de Cent Ans », dans La Politique par les armes. Conflits internationaux et politisation ( $X V^{e}-X I X^{e}$ siècle), dir. Laurent Bourquin, Philippe Hamon, Alain Hugon et Yann Lagadec, Rennes, PUR, 2014, p. 169-182. De nombreuses biographies de capitaines d'Écorcheurs ont été rédigées, dont: Jules Quicherat, Rodrigue de Villandrando, l'un des combattants pour l'indépendance française au $X V^{e}$ siècle, Paris, Hachette, 1879; Francis Rousseau, La Hire de Gascogne, Mont-de-Marsan, Lacoste, 1968 ; André Plaisse, Un Chef de guerre au XV siècle, Robert de Flocques. Bailli royal d'Évreux, Maréchal héréditaire de Normandie, Conseiller et chambellan du roi, Évreux, Société libre de l'Eure, 1984; Valérie Toureille, Robert de Sarrebrück ou l'honneur d'un écorcheur (v. 1400 v. 1462), Rennes, PUR, 2014. Comme l'a remarqué Philippe Contamine, les compagnies d'écorcheurs sont comparables aux Grandes Compagnies qui déferlèrent sur le royaume de France au XIV siècle: Philippe Contamine, «Les compagnies d'aventure en France pendant la Guerre de Cent Ans », Mélanges de l'École française de Rome. Moyen Âge, Temps modernes, vol. 87, $\mathrm{n}^{\circ} 2$, 1975, p. 365-396; Germain Butaud, Les Compagnies de routiers en France (1357-1393), Clermont-Ferrand, Lemme édit, 2012.

${ }^{7}$ C'est ainsi qu'ils sont nommés dans la correspondance de la ville de Strasbourg et dans les archives de la ville de Bâle (voir par exemple Alexandre Tuetey, Les Écorcheurs, op. cit., p. 104-105).

${ }^{8}$ Loïc Cazaux, «Les lendemains de la Praguerie. Révolte et comportement politique à la fin de la guerre de Cent Ans », dans François Pernot et Valérie Toureille (dir.), Lendemains de guerre... De l'Antiquité au monde contemporain: les hommes, l'espace et le récit, l'économie et le politique, Bruxelles, Peter Lang, 2010, p. 370371. 
maximum, annoncent des troupes de plus de 10000 hommes. C'est aussi dans ces années 1438-1439 que les Écorcheurs deviennent une préoccupation pour le pouvoir royal, qui tente de lutter tant bien que mal contre un phénomène qui le dépasse. Pourtant, malgré ce que cette amplification de l'écorcherie pourrait laisser croire, l'hiver 1438-1439 ne semble pas plus difficile que les précédents: les chroniqueurs ne rapportent aucun phénomène météorologique inhabituel qui pourrait impliquer une plus grande difficulté pour ces gens d'armes à subvenir à leurs besoins et, par conséquent, pourrait expliquer l'aggravation de la situation. Un phénomène extraordinaire dans un hiver ordinaire, en somme. Cela amène donc à se demander s'il y a un hiver pour les gens de guerre, que l'on décrit souvent dans l'attente de la belle saison propice aux campagnes militaires. Si c'est le cas, quelles sont les caractéristiques de la saison dite «morte» pour cette catégorie de population qui ne semble pas dépendre directement des aléas climatiques pour ses activités ou sa subsistance? Et si la question de l'hiver est secondaire pour eux, leur activité obéit-elle à une autre forme de périodicité ?

Pour répondre à ces questions, il faut se placer à hauteur d'Écorcheurs, ce qui pose le problème des sources. Nous ne possédons que très peu de sources émanant de ces gens de guerre, qui, de toute manière, ne souhaitent pas mettre en avant ces épisodes peu reluisants de leur carrière. Pour ne citer qu'un exemple, la Cronique Martiniane fut rédigée dans l'entourage d'Antoine de Chabannes, l'un des principaux capitaines d'Écorcheurs, mais relate de façon «euphémisée » ses exactions ${ }^{9}$. Les renseignements dont nous disposons proviennent donc

9 Cronique Martiniane, éd. Pierre Champion, Paris, Champion, 1907. Sur Antoine de Chabannes, voir l'intervention de Loïc Cazaux, "Antoine de Chabannes, capitaine d'écorcheurs et officier royal : fidélités politiques et pratiques militaires au $\mathrm{XV}^{\mathrm{e}}$ siècle », au colloque international Routiers et mercenaires d'Aquitaine, d'Angleterre et d'ailleurs (v. 1340-1453). Rôle militaire et impact sur les sociétés locales, tenu au château de Berbiguières les 13 et 14 septembre 2013 (visible sur: 
principalement des pouvoirs royal (ordonnances, lettres de rémission, correspondance), ducaux (notamment les enquêtes organisées dans le duché de Bourgogne visant à demander des réparations au roi et les comptes de celui de Lorraine) et municipaux (délibérations, correspondance $)^{10}$. Ces sources imposent donc au regard de l'historien un «filtre », celui du pouvoir dont elles émanent, qui rend difficile la compréhension de ce phénomène «de l'intérieur », d'autant qu'elles ont parfois tendance à noircir une situation déjà très difficile et qu'elles usent souvent de formules stéréotypées. Le risque est grand alors de penser qu'une certaine accoutumance s'est installée face à ces actes ${ }^{11}$. Finalement, ces sources, auxquelles il faut bien sûr ajouter les chroniques, elles-mêmes souvent rédigées dans les entourages royaux et ducaux, nous en disent plus sur la façon dont ces pouvoirs analysent et traitent ce problème que sur les Écorcheurs eux-mêmes. Toutefois, les renseignements fournis peuvent nous aider à préciser l'ampleur du phénomène durant cet hiver 1438-1439, en termes d'effectifs mais également dans sa dimension géographique. Ensuite, l'étude des causes de cette amplification de l'écorcherie permettra de déterminer dans quelle mesure la saison hivernale est un facteur explicatif. Cela permettra de mieux comprendre si et dans quelle mesure la sortie de l'hiver est synonyme d'une sortie de crise.

\section{Une « pestilence » qui ravage de nombreuses régions}

https://www.youtube.com/watch?v=YJXgAsSGFkE, consulté le $1^{\text {er }}$ décembre 2015).

10 De nombreux actes concernant les exactions des Écorcheurs et la réaction des pouvoirs ont été publiés dans: Marcel Canat, Documents inédits pour servir à l'histoire de Bourgogne, t. I, Chalon-sur-Saône, 1863, p. 197-485 ; Alexandre Tuetey, Les Écorcheurs, op. cit., t. II ; Joseph de Fréminville, Les Écorcheurs en Bourgogne, op. cit.

11 Michael Jucker, «Le butin de guerre au Moyen Âge. Aspects symboliques et économiques », art. cit., montre que les enquêtes ordonnées par le duc de Bourgogne après le passage des Écorcheurs en vue de demander réparation sont à prendre avec précaution. 
En qualifiant l'écorcherie de «pestilence ${ }^{12} »$, Monstrelet illustre bien ce qu'elle représente aux yeux des populations : se répandant partout comme la peste, elle est synonyme de carnage et sème la misère ${ }^{13}$. De fait, de nombreuses régions sont touchées durant cet hiver 1438-1439. Sans entrer dans les détails des parcours de chaque compagnie d'Écorcheurs, il est possible de distinguer deux principaux ensembles à l'œuvre. Le premier se forme à l'entrée de l'hiver sur les marches des duchés de Lorraine et de Bar par le rassemblement de plusieurs compagnies et ravage ces régions, puis l'Alsace, les régions de Bâle et de Francfort et la Bourgogne : les principaux chefs de cet agrégat sont, La Hire et son frère bâtard Pierre Renaud de Vignoles, Antoine de Chabannes, Blanchefort, Brusac, Chapelle, Alexandre, bâtard de Bourbon, le grand et le petit Estrac $^{14}$. Le second, moins important en termes d'effectifs mais non moins dévastateur, est dirigé par Rodrigue de Villandrando, associé à d'autres capitaines dont Poton de Xaintrailles, et ravage principalement le sud du royaume de France ${ }^{15}$.

Mais cette vision simplifiée ne doit pas masquer le caractère beaucoup plus complexe de la situation. D'une part, alors que les chroniqueurs ont tendance à traiter ces deux groupes comme des unités homogènes, ce sont des agrégats de compagnies qui n'obéissent qu'à leur capitaine. Celui-ci peut choisir de faire temporairement route à part ou permettre à ses hommes de se détacher, au gré de circonstances souvent dictées par l'appât du gain et les contraintes de logement : par exemple, le 28 novembre 1438, Pierre Florimond, de la compagnie

\footnotetext{
${ }^{12}$ Enguerran de Monstrelet, Chronique, op. cit., p. 350.

13 Frédéric Godefroy, Dictionnaire de l'ancienne langue française et de tous ses dialectes $d u I^{e}$ au $X V^{e}$ siècle, Paris, Vieweg, 1881, t. VI, p. 129.

14 Enguerran de Monstrelet, Chronique, op. cit., p. $349 . \quad$ Olivier de La Marche, Mémoires, éd. Henri Beaune et Jules d'Arbaumont, Paris, Renouard, t. I, 1883, p. 243 244.

${ }^{15}$ Ibid., p. 354-356. Jules Quicherat, Rodrigue de Villandrando, op. cit., p. 166-167. 
d'Antoine de Chabannes, et le sire de Saint-Prix, de la compagnie d'Alexandre, bâtard de Bourbon, viennent loger avec 300 hommes à Génelard, village situé au nord-ouest de Mâcon, qu'ils ne quittent que deux semaines plus tard ${ }^{16}$. D'autre part, il ne faut pas oublier qu'à côté de ces deux grands ensembles qui défraient les chroniques, d'autres compagnies, parfois d'une dizaine de personnes seulement, exercent leurs méfaits sur des territoires plus restreints ${ }^{17}$. De plus, les Anglais continuent leurs exactions, qui n'ont rien à envier à celles des Écorcheurs, notamment autour de Paris $^{18}$, ainsi que dans le nord et le sud-ouest du royaume $^{19}$. Suivre toutes ces compagnies pour retracer leurs parcours respectifs relève donc de la gageure et il ne s'agira ici que de rappeler les grandes étapes des pérégrinations des deux grands ensembles identifiés afin de tenter d'en saisir la logique ${ }^{20}$.

${ }_{16}$ Marcel Canat, Documents, op. cit., p. 467.
${ }^{17}$ En janvier-mars 1439, des Écorcheurs stationnent entre Vervins et Mézières : Jean-Marie Cauchies, «Les "écorcheurs" en Hainaut (1437-1445) », art. cit., p. 325).

18 Journal d'un bourgeois de Paris, éd. Alexandre Tuetey, Paris, Champion, 1881, p. 344-345.

19 À la fin du mois de janvier 1439, la ville d'Amiens organise sa défense pour faire face à une éventuelle attaque des Anglais basés à Gournay (Archives municipales, désormais AM, Amiens, BB 5, fol. 10v, échevinage du 24 janvier 1439). Le 7 mars 1438, la ville de Toulouse adresse des doléances à Charles VII : plusieurs de ces plaintes portent sur les exactions des Anglais et des routiers dans la région. Alors qu'elle dénonce celles de Villandrando, la ville explique qu'elle a dû faire appel à lui pour se défendre des Anglais, moyennant une rétribution en divers produits d'une valeur totale de 600 écus d'or, qui servent également à éviter son entrée dans la sénéchaussée: Philippe Wolff, «Doléances de la ville de Toulouse aux États de Languedoc de $1438 »$, Annales $d u$ Midi, t. 54-55, 1942-1943, p. 88-102, particulièrement p. 91 et 93. La réponse de Charles VII est révélatrice de son incapacité à intervenir : dans une lettre aux Toulousains du 10 avril, il ordonne de ne plus respecter les patis imposés par les Anglais et accorde l'immunité à ceux qui tueraient des Anglais : Marie-Jean-Célestin Douais, "Charles VII et le Languedoc, d'après un registre de la viguerie de Toulouse (1436-1448) », Annales du Midi, vol. 8, 1896, p. 142-145.

${ }^{20}$ Pour la reconstitution de leurs trajets, les travaux de référence restent ceux d'Alexandre Tuetey, Les Écorcheurs, op. cit., de Joseph de Fréminville, Les Écorcheurs en Bourgogne, op. cit. et de Jules Quicherat, Rodrigue de Villandrando, $o p$. cit. Les cartes publiées à la fin de cet article ne doivent pas faire oublier que les trajets des capitaines sont généralement moins linéaires que ce que leur représentation pourrait laisser penser. De plus, en raison de l'échelle utilisée pour ces cartes, il n'a 
Le premier groupe d'Écorcheurs naît avec la reprise en 1438 de la guerre entre Antoine de Vaudémont et René d'Anjou, duc de Lorraine, alors en Italie et soutenu par Charles VII ${ }^{21}$. De nombreuses compagnies en quête d'employeurs y voient l'occasion de s'engager dans l'un ou l'autre camp: les principaux capitaines servant le comte de Vaudémont sont Forte-Épice, Antoine de Chabannes, Robert de Flocques, Blanchefort ${ }^{22}$; le maréchal de Lorraine emploie, quant à lui, La Hire, Poton de Xaintrailles, le grand et le petit Estrac, Wanchelin de La Tour et le bâtard de Vertus ${ }^{23}$. Parmi ceux-ci, certains, comme La Hire, sont envoyés par Charles VII pour soutenir le roi René. Plusieurs milliers d'hommes d'armes sont donc recrutés pour ce conflit qui ressemble davantage à une démonstration de forces armées qui ravagent le plat pays, prennent et perdent des places ${ }^{24}$. Ainsi Mirecourt est-elle prise par Forte-Épice le 28 octobre pour le comte de Vaudémont puis reprise en décembre par La Hire en échange de 5000 saluts d'or ${ }^{25}$, qui servent aussi à faire changer de camp le capitaine tenant alors la place, Robert de Flocques ${ }^{26}$. De même, Robert de Sarrebrück est sous les ordres du comte de Vaudémont en septembre $1438^{27}$, puis entre au

pas été possible de représenter les différents groupes d'Écorcheurs sous les ordres d'un même capitaine et qui opèrent simultanément dans des localités différentes. Les documents publiés par les auteurs précédemment cités, ainsi que ceux édités par Marcel Canat, Documents, op. cit., surtout les enquêtes réalisées en Bourgogne, permettent de préciser la géographie de leurs exactions à l'échelle locale : sur une aire de quelques kilomètres carrés, une compagnie est souvent scindée en plusieurs groupes occupant chacun un village.

${ }^{21}$ Voir carte 1.

${ }^{22}$ Enguerran de Monstrelet, Chronique, op. cit., p. 336-337.

${ }^{23}$ Philippe de Vigneulles, Chronique, éd. Charles Bruneau, Metz, Société d'histoire et d'archéologie de Lorraine, t. II, 1929, p. 254.

${ }^{24}$ Bertrand Schnerb, Bulgnéville (1431). L'État bourguignon prend pied en Lorraine, Paris, Economica, 1993, p. 113-114.

${ }^{25}$ Philippe de Vigneulles, Chronique, op. cit., p. 254.

26 Robert de Flocques figure au service du roi René dans les comptes d'Othin d'Amance, receveur général de Lorraine, à partir du 15 décembre 1438 : Henri Lepage, «Extrait des comptes du receveur général de Lorraine relatifs à la seconde guerre entre René $\mathrm{I}^{\mathrm{er}}$ et Antoine de Vaudémont », Recueil de documents sur l'histoire de Lorraine, t. I, 1855, p. 146.

${ }^{27}$ Philippe de Vigneulles, Chronique, op. cit., p. 252-253. 
Grand conseil du roi René au mois de novembre suivant ${ }^{28}$. Ainsi, un grand nombre de capitaines d'Antoine de Vaudémont, comme Antoine de Chabannes et Blanchefort, lui font défection et se rallient à son adversaire $^{29}$. Durant cette guerre, une grande partie des ressources financières est donc consacrée à l'achat de ces capitaines.

Mais cette politique a son revers: les effectifs deviennent trop importants pour pouvoir occuper tous ces hommes dans ce conflit et, par conséquent, le danger est grand de les voir vivre sur les terres de leur employeur. Un accord est donc conclu entre Isabelle d'Anjou et les capitaines d'Écorcheurs, dont La Hire, Antoine de Chabannes et Robert de Flocques, pour acheter le départ de ces encombrants soldats ${ }^{30}$, «auquel département ilz eurent très grand finance des dictes duchées de Bar et de Lohoraine, et avec ce emmenèrent ostaiges avec eulx pour estre payés du surplus ${ }^{31} »$. Indésirables dans le royaume de France, d'où Charles VII a chargé La Hire de les éloigner ${ }^{32}$, indésirables dans le duché de Lorraine, ils se dirigent vers l'Alsace, La Hire jurant, d'après une tradition messine, qu'il fera boire l'eau du Rhin à son cheval ${ }^{33}$ : ils sont

${ }^{28}$ Valérie Toureille, Robert de Sarrebrück, op. cit., p. 131.

29 Enguerran de Monstrelet, Chronique, op. cit., p. 337. Antoine de Chabannes, qui tient Vézelise pour le comte de Vaudémont, se rallie contre 3500 vieux florins le 19 décembre 1438 et Blanchefort contre 900 vieux florins dont il donne quittance le 20 février 1439: Auguste Vallet de Viriville, «Documents inédits sur La Hire, Chabannes et autres capitaines du XV siècle », Bulletin de la Société de l'Histoire de France, vol. II, 1859-1860, p. 37-38.

${ }^{30}$ Alexandre Tuetey, Les Écorcheurs, op. cit., p. 69-71.

${ }^{31}$ Enguerran de Monstrelet, Chronique, op. cit., p. 338.

32 Dans une lettre du $1^{\text {er }}$ mars 1438, Charles VII a ordonné à La Hire, bailli de Vermandois, et à d'autres baillis de faire partir les Écorcheurs de Champagne : lettre publiée par Pierre Champion, Guillaume de Flavy, capitaine de Compiègne. Contribution à l'histoire de Jeanne d'Arc et à l'étude de la vie militaire et privée au $X V^{e}$ siècle, Paris, Champion, 1906, p. 205-207. En juillet-août, la ville de Châlons-enChampagne fait appel à La Hire pour faire partir Robert de Flocques, qui ravageait la région: le bailli de Vermandois reçoit 200 écus d'or pour cette opération : AM Châlons-en-Champagne, BB 3, fol. 61r et 63r. André Plaisse, Robert de Flocques, op. cit., p. 60-61.

${ }^{33}$ Philippe de Vigneulles, Chronique, op. cit., p. 256. 
dans les environs de Strasbourg fin février ${ }^{34}$. En mars, les Écorcheurs poursuivent vers Bâle, où la présence de prélats au concile visant à déposer Eugène IV peut leur laisser espérer de substantiels gains ${ }^{35}$. Les Allemands tentent de s'organiser militairement pour les repousser ${ }^{36}$, mais le moyen le plus efficace pour se débarrasser de ces indésirables reste l'achat de leur départ: d'après Jean de Stavelot, les clercs de Bâle leur versent 16000 florins $^{37}$.

La plupart des Écorcheurs semble alors se diriger vers la Bourgogne, qui n'a pas été épargnée pendant tout cet hiver. Effectivement, dès le 15 septembre 1438, l'inquiétude grandissait comme en témoigne une lettre de Charles VII qui, suite à une demande du duc, interdit aux capitaines d'Écorcheurs d'entrer sur les terres de Bourgogne ${ }^{38}$. Mais cet ordre est suivi de peu d'effets: en octobre, Blanchefort et Antoine de Chabannes se voient promettre 2500 saluts d'or et deux coursiers d'une valeur de 200 saluts pour prix de leur départ ${ }^{39}$. Les espèces sonnantes et trébuchantes sont visiblement jugées plus efficaces. Mais, s'ils partent, c'est pour stationner en Charolais durant les deux premières semaines de novembre ${ }^{40}$. Durant tout l'hiver 1438-1439, des Écorcheurs sillonnent la Bourgogne ${ }^{41}$, accentuant la crainte de voir des

\footnotetext{
${ }^{34}$ Alexandre Tuetey, Les Écorcheurs, op. cit., p. 102.

${ }^{35}$ Enguerran de Monstrelet, Chronique, op. cit., p. 349.

${ }^{36}$ Ibid. Le mois de mars est marqué par une intense activité épistolaire entre les villes de Strasbourg, Berne, Bâle et les comtes palatins du Rhin pour organiser une défense collective avec la levée de troupes: Alexandre Tuetey, Les Écorcheurs, op. cit., p. 107-109.

${ }^{37}$ Jean de Stavelot, Chronique, éd. Adolphe Borgnet, Bruxelles, Hayez, 1861, p. 432.

${ }^{38}$ Cette lettre est publiée par Alexandre Tuetey, Les Écorcheurs, op. cit., p. 39-41. Les capitaines à qui s'adresse cet ordre y sont nommés : Poton de Xaintrailles, Brusac, le bâtard de Bourbon, le bâtard de Harcourt, le bâtard de Vertus, Rodrigue de Villandrando, Antoine de Chabannes, Robert de Flocques, Blanchefort, le bâtard de Culan, le bâtard de Sorbier et Florimont.

39 Joseph de Fréminville, Les Écorcheurs en Bourgogne, op. cit., p. 90.

${ }^{40}$ Marcel Canat, Documents, op. cit., p. 464.

${ }^{41}$ Gaudifer de Malerey et Jean d'Auton sont en Charolais en décembre 1438 (ibid., p. 459).
} 
milliers de pillards fondre sur un duché et un comté déjà bien ravagés depuis le traité d'Arras ${ }^{42}$. Cette crainte se transforme parfois en rumeur : en novembre, des informations laissent entendre que Rodrigue de Villandrando, alors dans le Bordelais avec 14000 hommes, envisagerait de se diriger vers le duché de Bourgogne ; aussitôt, des fonds sont levés pour organiser la défense. Finalement, ces renseignements se révèlent faux mais la même rumeur refait son apparition à Besançon en mars, signe de l'effroi provoqué par ces troupes parfois lointaines ${ }^{43}$.

C'est surtout à la fin de l'hiver que les terres bourguignonnes, qui, jusque-là, ont été contournées par les Écorcheurs, se trouvent confrontées au problème. Le 20 février, une lettre du seigneur de Ternant avertit le gouverneur de Bourgogne de la présence à Gien de 10000 Écorcheurs sous les ordres de Robert de Flocques, Antoine de Chabannes et Blanchefort ${ }^{44}$. Quelques jours plus tard, des troupes dirigées par, entre autres, le bâtard de Bourbon et Robert de Flocques et estimées par les témoins à 8000 chevaux font irruption en Charolais ${ }^{45}$. Voici ce que racontent huit témoins à propos de leur incursion à Paray-le-Monial :

[...] et lors feirent tres grands et innumerables maulx, exces et domaiges, car ils apprisonnoient tous ceulx [qu'ils] pouvoient rencontrer, les ransonnoient et apprisonnoient dedans les arches [coffres], leurs chauffoient les pies et les bastoient tres fort, violoient les eglises et les femes qu'ils prenoient $[\ldots]^{46}$.

Puis les routiers qui étaient à Bâle entrent en Bourgogne par Montbéliard

\footnotetext{
${ }^{42}$ Pour plus de détails sur l'écorcherie en Bourgogne durant les années 1438-1439, voir Joseph de Fréminville, Les Écorcheurs en Bourgogne, op. cit., p. 89-125.

43 Ibid., p. 96-98. Jules Quicherat, Rodrigue de Villandrando, op. cit., p. 168-169 et 309-312.

${ }^{44}$ Lettre publiée par Joseph de Fréminville, Les Écorcheurs en Bourgogne, op. cit., p. 234-235.

${ }^{45}$ Marcel Canat, Documents, op. cit., p. 459.

${ }^{46}$ Ibid.
} 
vers la mi-mars ${ }^{47}$. Des troupes passant par le village de Grandvillars, à l'est de Montbéliard, mettent à mort cinquante petits enfants ${ }^{48}$. Monstrelet précise que, de Bourgogne, des Écorcheurs vont dans le Nivernais puis en Auvergne $^{49}$, mais d'autres groupes continuent de ravager le duché pendant encore plusieurs mois: une enquête de 1444 révèle que, début avril, Blanchefort, Antoine de Chabannes et Chapelle passent deux semaines aux environs de Luxeuil, y commettant toutes sortes de crimes avec leurs 5 ou 6000 hommes ${ }^{50}$.

Au total, combien sont ces Écorcheurs qui ravagent les régions de l'est ? Il est très difficile de répondre à cette question. Cela tient à la nature des sources. Le héraut Berry qui est favorable à Charles VII et tend donc à minimiser les exactions des capitaines français estime les effectifs à 800 lances et $2000 \operatorname{archers}^{51}$. Mais les chroniques des régions pillées avancent des effectifs beaucoup plus importants. Le bourguignon Monstrelet parle de «six mille chevaulx ${ }^{52}$ au départ de Lorraine et ajoute que «si multiplioient chescun jour la compaignie des malvais. [...] Et tant qu'ilz se trouvèrent bien telle fois fut, bien en nombre de dix mille $^{53} »$. Jean de Stavelot, à partir des informations qu'il obtient à Liège, parle de 15000 hommes et femmes, laissant ainsi transparaitre la présence de non-combattants ${ }^{54}$. Toutefois, ces chiffres participent d'une dramatisation de la situation: Monstrelet les fournit après avoir rappelé «les maulx innumérables» dont ces hommes se rendent coupables ${ }^{55}$;

\footnotetext{
${ }^{47}$ Alexandre Tuetey, Les Écorcheurs, op. cit., p. 115-116.

${ }^{48}$ André Plaisse, Robert de Flocques, op. cit., p. 68.

${ }^{49}$ Enguerran de Monstrelet, Chronique, op. cit., p. 350.

${ }^{50}$ Alexandre Tuetey, Les Écorcheurs, op. cit., p. 117-118. Enquête publiée dans ibid., t. II, p. 309-380.

51 Gilles le Bouvier dit le Héraut Berry, Les Chroniques de Charles VII, éd. Henri Courteault et Léonce Celier, Paris, Klincksieck, 1979, p. 198.

${ }_{53}^{52}$ Enguerran de Monstrelet, Chronique, op. cit., p. 349.

${ }^{53}$ Ibid., p. 350.

${ }^{54}$ Jean de Stavelot, Chronique, op. cit., p. 432.

${ }^{55}$ Enguerran de Monstrelet, Chronique, op. cit., p. 350. 
Jean de Stavelot les donne après avoir décrit le parcours des Écorcheurs «destrusant et ranchonant partout les paiis ${ }^{56}{ }$. Il s'agit donc autant d'un procédé littéraire visant à retranscrire chez le lecteur l'effroi ressenti par les populations que d'une volonté de dénoncer les exactions d'hommes d'armes souvent présentés par ces auteurs comme des «Armagnacs » ou des «Français », c'est-à-dire des ennemis ${ }^{57}$. Les nombreuses lettres échangées lors de leurs incursions en Alsace et en Allemagne fournissent également des estimations contradictoires. Celles adressées par la ville de Strasbourg et le margrave de Hochberg à la ville de Bâle fournissent un chiffre de 12000 Écorcheurs $^{58}$. Comme l'objectif de ces correspondances n'est pas seulement de renseigner mais aussi de demander des secours et de mobiliser de potentiels alliés face à ces troupes, il a peut-être été tentant pour les rédacteurs de noircir la situation. D'ailleurs, Alexandre Tuetey cite une lettre de la ville d'Haguenau, en date du 2 mars 1439, conservée aux archives municipales de Strasbourg, qui annonce un effectif de 5000 chevaux $^{59}$.

Pour prendre la mesure du phénomène et tenter de dépasser ces différences d'appréciations entre les sources, il faut comparer ces chiffres à ceux fournis par les mêmes chroniqueurs pour les précédents épisodes d'écorcherie. Ainsi, Monstrelet estime à «environ [...] deux mil chevaulx » le nombre d'Écorcheurs qui partirent de Normandie pour aller piller le Hainaut durant l'hiver 1437-1438, parmi lesquels figurent déjà Antoine de Chabannes, Pierre Renaud de Vignoles, Blanchefort et Robert de Flocques $^{60}$. On peut donc estimer que, en raison du regroupement de

\footnotetext{
${ }^{56}$ Jean de Stavelot, Chronique, op. cit., p. 431-432.

57 Ces deux termes sont souvent utilisés par les contemporains, notamment les chroniqueurs bourguignons, pour désigner les Écorcheurs : Enguerran de Monstrelet, Chronique, op. cit., p. 340, parle des « François, qu'on nommoit en commun langaige les Escorcheurs ».

${ }_{58}^{5}$ Alexandre Tuetey, Les Écorcheurs, op. cit., p. 103-104.

${ }^{59}$ Ibid., p. 104.

${ }^{60}$ Enguerran de Monstrelet, Chronique, op. cit., p. 316.
} 
nombreuses compagnies sur un petit territoire, l'écorcherie de l'hiver 1438-1439 devait apparaître aux yeux des contemporains comme un épisode inhabituel, l'augmentation des effectifs entraînant inévitablement un accroissement des dommages causés.

Le deuxième grand groupe d'Écorcheurs sillonne le sud du royaume et est commandé par Rodrigue de Villandrando ${ }^{61}$. Début novembre 1438, le capitaine castillan se trouve en Bordelais, où il a mené durant l'été une expédition l'ayant conduit à tenter de prendre la ville de Bordeaux, sans succès ${ }^{62}$. Plusieurs troupes opèrent alors dans le sud du royaume: Poton de Xaintrailles l'accompagne dans son expédition en Guyenne et en Gascogne ; Gui, bâtard de Bourbon, est en Languedoc, causant avec d'autres capitaines des dommages qui préoccupent le roi. Celui-ci ordonne à Poton de Xaintrailles d'aller à Toulouse pour reconduire ces indésirables en Guyenne, rejoignant ainsi Villandrando ${ }^{63}$. Toutes ces jonctions faites, ce sont 14000 hommes qui se concentrent au début de l'hiver dans une région exsangue, estime un mémoire adressé par les nobles au gouvernement anglais ${ }^{64}$. L'objectif étant là aussi de demander de l'aide, il faut prendre ce chiffre avec précaution. Mais, aux dires de Monstrelet, au début 1438, Rodrigue de Villandrando disposait de 1600 chevaux $^{65}$ : quel que soit le degré de réalisme de ces estimations, les effectifs ont donc certainement augmenté au cours de l'année.

Pour Charles VII, la crainte est grande de voir migrer tous ces gens de guerre vers le Languedoc pour y passer l'hiver. C'est ce qu'il exprime dans une lettre du 15 novembre 1438, où il demande aux habitants de la région de payer une contribution pour financer leur stationnement hivernal

\footnotetext{
${ }^{61}$ Voir carte 2.

62 Sur cette expédition, voir Jules Quicherat, Rodrigue de Villandrando, op. cit., p. $151-160$.

${ }^{63}$ Ibid., p. $158-159$.

${ }^{64}$ Ibid., p. 159.

${ }^{65}$ Enguerran de Monstrelet, Chronique, op. cit., p. 354. 
en Guyenne, où ils gêneront surtout les Anglais, et éviter ainsi qu'ils ne viennent dévaster la région ${ }^{66}$. Mais Rodrigue de Villandrando, Poton de Xaintrailles et Gui, bâtard de Bourbon, entrent bientôt en Comminges à l'appel du comte d'Armagnac alors en conflit avec Mathieu de Foix ${ }^{67}$. Puis ils vont dans la sénéchaussée de Carcassonne mais la ville organise une défense qui permet de les repousser partiellement ${ }^{68}$. Fin novembre, les trois capitaines arrivent à proximité de Perpignan et tentent en vain de prendre Salces ${ }^{69}$. S'installant dans la région, ils suscitent la crainte chez les rois d'Aragon et de Navarre, qui commencent à organiser la défense en vue d'une éventuelle incursion au printemps, l'hiver les protégeant d'un franchissement de la barrière montagneuse des Pyrénées ${ }^{70}$. Comme en Bourgogne à la même époque, la réputation de cette redoutable masse d'Écorcheurs, sous les ordres de capitaines connus aussi bien pour leurs faits d'armes glorieux au service du roi de France que pour leurs exactions, crée une panique conduisant à la mise en défense de régions qui sont pour lors hors de leur portée. Alors que les rois d'Aragon et de Navarre craignent une traversée de leurs territoires vers la Castille, où le roi Jean II est en conflit avec sa noblesse et a besoin de troupes, le capitaine castillan prend la direction de Toulouse et s'empare de Villemur-sur-Tarn au début de l'année 1439. Souffrant du contrôle des axes de communication par les Écorcheurs et du pillage des campagnes environnantes, Toulouse finit par acheter leur départ en mars-

\footnotetext{
${ }^{66}$ Lettre publiée par Jules Quicherat, Rodrigue de Villandrando, op. cit., p. 313-314.

67 Hélène Biu, «Du panégyrique à l'histoire: l'archiviste Michel de Bernis, chroniqueur des comtes de Foix (1445)», Bibliothèque de l'École des Chartes, vol. 160, 2002, p. 458.

68 Jean de Salazar, lieutenant de Rodrigue de Villandrando, et le bâtard de Béarn restent encore plusieurs mois dans le Lauragais (Jules Quicherat, Rodrigue de Villandrando, op. cit., p. 165-166).

69 Jerónimo Zurita, Anales de la Corona de Aragón, éd. Ángel Canellas López, Zaragoza, Institución Fernando el Católico, t. 7, 1975, p. 183.

${ }^{70}$ Jules Quicherat, Rodrigue de Villandrando, op. cit., p. 167-168.
} 
$\operatorname{avril}^{71}$.

Au final, si l'on se fie aux estimations des contemporains, ce sont entre 20000 et 30000 Écorcheurs qui sèment le désordre dans le royaume de France et ses marges durant 1'hiver 1438-1439. Leur champ d'action couvre plusieurs centaines de kilomètres carrés dans des régions instables où les pouvoirs ont parfois autant besoin d'eux, notamment en cas de guerre, que de se défendre d'eux. Leur rapidité de mouvement donne parfois une impression d'ubiquité et est une arme efficace pour surprendre les populations ciblées, suscitant la peur jusque dans des régions éloignées de leur champ d'action.

\section{Un simple problème d'hivernage pour les Écorcheurs?}

L'hiver 1438-1439 est donc particulièrement difficile à la fois pour les populations locales, qui doivent subir le passage de milliers d'hommes d'armes, et pour les Écorcheurs, qui recherchent des moyens de subsistance, soit par l'emploi dans des guerres, soit par le pillage, l'appatissement et le rançonnement des personnes et du bétail. La lettre de Charles VII aux Toulousains en date du 15 novembre 1438 pose ainsi le problème à propos des troupes de Rodrigue de Villandrando et de Poton de Xaintrailles :

[...] pour supporter nostre pays de Languedoc et affin qu'ilz n'y entrent ny s'y viengnent yverner, comme déjà aucuns d'eulz avoient commencé et y estoient entrez, qui seroit la destruction dudit pays et de noz subgiez et habitans d'icelluy, leur avons mandé très expressement qu'ilz se demeurent en nostre dit duchié et pays de là Garonne, toute ceste morte sayson $[\ldots]^{72}$.

Le roi explique donc un éventuel passage des Écorcheurs en Languedoc

\footnotetext{
${ }^{71}$ Ibid., p. $169-171$ et 318-323.

${ }^{72}$ Lettre publiée dans ibid., p. 313-314. 
dans une perspective saisonnière : ces professionnels de la guerre doivent «yverner», ce qui implique de se nourrir en «ceste morte sayson» caractérisée par l'absence de campagne militaire pourvoyeuse d'emplois $^{73}$. Cette analyse traditionnelle se retrouve dans les chroniques et la littérature médiévales et est généralement reprise par les historiens. Pourtant, on l'a vu, l'activité des Écorcheurs durant l'hiver 1438-1439 montre que cette conception saisonnière de l'activité des gens de guerre est insuffisante: elle ne parvient pas à expliquer l'importance de ce phénomène, notamment l'augmentation des effectifs au cours de leurs pérégrinations, d'autant que les sources ne nous ont pas laissé le souvenir d'un hiver difficile du point de vue météorologique. Il n'y a donc pas de corrélation entre l'ampleur de cette écorcherie et les contraintes climatiques de la saison hivernale. D'autres facteurs explicatifs doivent être pris en compte.

Le premier tient à la situation géopolitique née de la signature du traité d'Arras en 1435. Le lien entre celui-ci et l'écorcherie est connu : le roi de France et le duc de Bourgogne mettant fin à la guerre civile née au début $\mathrm{du} \mathrm{Xv}^{\mathrm{e}}$ siècle ${ }^{74}$, de nombreux hommes d'armes se retrouvent sans emploi et se livrent au pillage, notamment des terres bourguignonnes ${ }^{75}$. Mais, là encore, cela n'explique que partiellement l'ampleur de l'écorcherie de l'hiver 1438-1439, qui atteint des effectifs jusque-là inconnus. En réalité, après ce traité, il y a encore des occasions pour ces routiers de se faire engager. Ainsi, la paix avec le duc de Bourgogne permet à Charles VII de concentrer ses forces sur les Anglais : dès l'automne 1435, profitant d'une révolte des Normands, il organise une expédition dans le pays de Caux, à laquelle participent, entre autres,

\footnotetext{
${ }^{73}$ Dans la suite de cette lettre, Charles VII évoque « la très grant cherté de vivres » en Guyenne : ibid., p. 314.

74 Sur cette guerre civile, voir Bertrand Schnerb, Armagnacs et Bourguignons. La maudite guerre, 1407-1435, Paris, Perrin, 1988.

${ }^{75}$ Olivier de La Marche, Mémoires, op. cit., p. 245.
} 
Robert de Flocques, La Hire et Poton de Xaintrailles, qui parviennent aux portes de Rouen au début de l'année $1436^{76}$; Paris est prise en avril 1436 et Montereau-Fault-Yonne en octobre 1437. De son côté, Philippe le Bon tente de prendre Calais aux Anglais en juin-juillet 1436 et réprime la révolte de Bruges en 1437. Il y a donc des occasions d'embauche mais le caractère ponctuel de ces opérations, qui ne durent pas plus de deux mois, et l'absence de grande campagne mobilisant des effectifs importants ne permettent pas à tous les hommes d'armes de se faire engager et les troupes inoccupées se livrent à toutes sortes d'exactions ${ }^{77}$. Cette précarité explique pourquoi Rodrigue de Villandrando se retrouve dans le Bordelais au début de l'hiver 1438-1439: chassé du Berry par l'armée de Charles VII après en avoir tué le bailli, il pille au début de l'année le Quercy et le Périgord puis jette son dévolu sur la Guyenne anglaise à partir du mois de mai, prenant plusieurs villes et places fortes et tentant de s'emparer de Bordeaux ${ }^{78}$. C'est un échec mais cette opération, qui n'a pas été ordonnée par le roi, lui permet un retour en grâce auprès de celui-ci, comme l'explique Monstrelet :

Pour lesquelles entreprinses vaillances et diligences que fist ycelui Rodighe de Villandras ou pays de Bordeaulx, le Roy de France lui pardonna toutes les offences et malfais qu'il avoit fais contre luy ${ }^{79}$.

\footnotetext{
${ }^{76}$ Enguerran de Monstrelet, Chronique, op. cit., p. 204, 281-282 et 297-298. Héraut Berry, Les Chroniques de Charles VII, op. cit., p. 175.

${ }^{77}$ Ainsi, alors que La Hire participe au siège de Calais où il est blessé à la jambe (Enguerran de Monstrelet, Chronique, op. cit., p. 245), les garnisons françaises de Gerberoy et de Clermont-en-Beauvaisis ne cessent de détrousser les marchands de la ville de Beauvais, au point qu'on songe à demander des secours au connétable, à La Hire et à Poton de Xaintrailles: AM Beauvais, coll. Bucquet-aux-Cousteaux, t. LV-LVI, p. 146.

${ }^{78}$ Philippe Lauer, «Un nouveau document sur Rodrigue de Villandrando. Le meurtre de Giraud de Goulart, bailli de Berry (1437) », Bibliothèque de l'École des Chartes, vol. 80, 1919, p. 145-151. Giraud de Goulart est remplacé par Poton de Xaintrailles dans la fonction de bailli de Berry.

79 Enguerran de Monstrelet, Chronique, op. cit., p. 356. Sur cette expédition en Quercy, en Périgord et en Guyenne, voir Jules Quicherat, Rodrigue de Villandrando, 
Lorsque les Anglais en sont les cibles, les pillages deviennent donc des «vaillances»! Bel exemple de récupération d'une initiative personnelle par le pouvoir royal. Celui-ci n'a d'ailleurs organisé aucune opération militaire d'envergure en cette année 1438 et c'est pourquoi les troupes inoccupées sont amenées à divaguer. Cette divagation les conduit naturellement vers les territoires frontaliers de l'est et du sud, là où les conflits peuvent fournir des emplois, mais aussi là où le pillage de territoires ennemis du royaume de France est moins gênant pour Charles VII, que ces capitaines servent par ailleurs : La Hire est bailli de Vermandois depuis 1429, Rodrigue de Villandrando écuyer de l'écurie du roi depuis 1430 et chambellan du roi depuis fin 1432-début 1433 et Poton de Xaintrailles bailli de Berry depuis 1437.

À cette situation géopolitique amenant les hommes d'armes à vivre sur le pays, s'ajoutent les nombreuses difficultés auxquelles doivent faire face les populations. De l'avis général des chroniqueurs, l'année 1438 est très difficile dans beaucoup de régions. Une « grant mortalité ${ }^{80} »$ survient suite à une épidémie, apparemment de petite vérole : Jean Chartier estime le nombre de morts à Paris à 50000 personnes $^{81}$, à tel point que Jean Maupoint note que «le sonner pour les trespasséz fut defendu à Paris ${ }^{82}$ »; Philippe de Vigneulles écrit que 20000 personnes sont mortes à Metz et dans la région cette année-làa ${ }^{83}$.

Cette forte mortalité est facilitée par l'affaiblissement des organismes résultant de la famine qui sévit à la même époque. Partout, en raison des intempéries du printemps 1438, les prix des céréales et du vin

op. cit., p. 148-158.

Héraut Berry, Les Chroniques de Charles VII, op. cit., p. 197. Philippe de Vigneulles, Chronique, op. cit., p. 252.

81 Jean Chartier, Chronique de Charles VII, éd. Auguste Vallet de Viriville, Paris, P. Jannet, 1858, t. I, p. 246.

82 Jean Maupoint, Journal parisien, 1437-1469, éd. Gustave Fagniez, Paris, Champion, 1878, p. 25.

${ }^{83}$ Philippe de Vigneulles, Chronique, op. cit., p. 252. 
augmentent fortement, si bien que la ville de Metz prend des dispositions pour limiter cette envolée des prix $^{84}$ : en mai, un édit interdit de sortir du blé ou du pain de la ville, ce qui a pour effet de faire baisser les prix ${ }^{85}$; mais ce n'est que temporaire car les mauvaises récoltes de l'été amènent la ville à réglementer le poids des pains en septembre ${ }^{86}$; en octobre, seuls les boulangers ont le droit d'acheter du pain ${ }^{87}$. L'hiver 1438-1439 s'annonce donc difficile d'un point de vue alimentaire, d'autant que la menace d'une incursion d'Écorcheurs dans la région commence à se faire sentir : Philippe de Vigneulles rapporte la prise de Mirecourt par ForteÉpice pour le comte de Vaudémont le 28 octobre $^{88}$. À Liège, des messes et des processions sont organisées le 18 juin et le 22 septembre pour la cherté du blé, l'épidémie qui décime la population et le concile de Bâle ${ }^{89}$. En pure perte car, durant l'automne, les habitants manquent cruellement de pain et de blés ${ }^{90}$. Dans le sud du royaume, la situation semble être comparable: les prix sont élevés durant l'année $1438^{91}$ et Charles VII évoque «la très grant cherté de vivres ${ }^{92}{ }^{2}$ dans sa lettre aux Toulousains du 15 novembre.

À Paris, le Journal d'un bourgeois de Paris nous indique que la ville manque de pain en avril et de «verdure» en mai ${ }^{93}$. Il en rend responsables les bandes de « larrons $»^{94}$ et d'Anglais sévissant autour de la

\footnotetext{
${ }^{84}$ Le Héraut Berry, Les Chroniques de Charles VII, op. cit., p. 197, parle de «grant pluie ». Le Journal d'un bourgeois de Paris, op. cit., p. 339, note qu'au printemps il y a « force de pluye ». Il ajoute que le début de l'année est froid (ibid.) et que, le 24 juin, il fait aussi froid qu'en février ou mars (ibid., p. 340).

${ }^{85}$ Philippe de Vigneulles, Chronique, op. cit., p. 251.

${ }^{86}$ Ibid., p. 253.

${ }^{87} \mathrm{Ibid}$.

${ }^{88}$ Ibid., p. 254.

${ }^{89}$ Jean de Stavelot, Chronique, op. cit., p. 392 et 396-397.

${ }^{90}$ Ibid., p. 398.

91 Germain Lefèvre-Pontalis, «Petite chronique de Guyenne jusqu'à l'an 1442 », Bibliothèque de l'École des Chartes, vol. 47, 1886, p. 65.

${ }^{92}$ Jules Quicherat, Rodrigue de Villandrando, op. cit., p. 314.

93 Journal d'un bourgeois de Paris, op. cit., p. 339.

${ }^{94}$ Ibid., p. 338.
} 
capitale $^{95}$. En effet, depuis plusieurs mois, ils perturbent l'approvisionnement de la ville et provoquent une situation de disette, voire de famine $^{96}$, qu'aggravent les intempéries ${ }^{97}$. Poussant la dramatisation jusqu'à l'extrême, l'auteur évoque même la présence de loups dans la capitale à la fin de l'année 1438 : « en ce temps venoient les loups dedans Paris par la riviere et prenoient les chiens, et si mengerent ung enffant de nuyt $[\ldots]^{98} \gg$. À cette époque, les campagnes franciliennes sont peuplées de loups mais l'auteur exagère leur dangerosité en utilisant la croyance, bien ancrée au Moyen Âge, en l'anthropophagie du loup. Horreur suprême : c'est un enfant qui en est la victime. Boris Bove a montré que les mentions de loups dans le Journal d'un bourgeois de Paris peuvent être comprises comme des métaphores pour désigner les hommes de guerre se livrant à des pillages ${ }^{99}$. Qu'elle soit réelle, ce qui implique qu'ils n'arrivent plus à trouver leur nourriture dans les campagnes et doivent la chercher en ville, ou métaphorique, ce qui montre que la région parisienne n'est pas totalement sous le contrôle du pouvoir royal, la présence de loups dans les rues de la capitale met en évidence les difficultés d'une population en proie aux problèmes de subsistance et aux attaques d'hommes d'armes.

Cette conjoncture explique l'importance des effectifs d'Écorcheurs durant l'hiver 1438-1439 :

[...] et toutes fois qu'il venoit à Paris gens d'armes pour acconvoyer aucuns biens qu'on y amenoit, ilz amenoient avec eux II $^{\mathrm{c}}$ ou III $^{\mathrm{c}}$ mesnaigers, pour ce qu'ilz mouroient de fain à

\footnotetext{
${ }^{95}$ Ibid., p. 340-341.

${ }^{96}$ Ibid., p. 337-338.

${ }^{97}$ Ibid., p. 339-340.

${ }^{98}$ Ibid., p. 343.

99 Boris Bove, «Violence extrême, rumeur et crise de l'ordre public : la tyrannie du bâtard de Vaurus (1422) », dans Violences souveraines au Moyen Âge. Travaux d'une école historique, dir. François Foronda, Christine Barralis et Bénédicte Sère, Paris, PUF, 2010, p. 123-132.
} 
Paris $^{100}$.

Fuyant la faim, de nombreuses personnes rejoignent les bandes d'Écorcheurs. Elles espèrent ainsi bénéficier à la fois de leur protection et des recettes des pillages: les proies deviennent des prédateurs. Au Moyen Âge, les armées entraînent dans leur sillage des non-combattants, vagabonds, clercs, artisans, marchands, épouses parfois, prostituées souvent ${ }^{101}$, et les Écorcheurs n'échappent pas à la règle : Jean de Stavelot dénombre $« \mathrm{XV}^{\mathrm{M}}$ hommes et femmes ${ }^{102} »$. La lettre de la ville d'Haguenau, en date du 2 mars 1439, fournit des détails intéressants :

Les Armagnacs n'ont pas plus de cinq mille chevaux et dans ce nombre trois mille bien montés, le reste n'est qu'un ramassis au milieu duquel il y a trois cents femmes à cheval [...] la nuit venue ils se couchent à peu de distance les uns des autres, mangent mal, se contentent souvent de noix et de pain, mais nourrissent bien leurs chevaux $[\ldots]^{103}$.

Ainsi, la situation économique des villes décrite par les sources explique l'augmentation des effectifs constatée par Monstrelet au cours de leurs pérégrinations dans l'est. Mais les compagnies sont elles aussi victimes de cette famine hivernale, que les pillages ne parviennent pas à résorber : il doit être difficile de trouver de la nourriture pour ces effectifs nombreux dans des régions où elle manque. À l'origine simple phénomène militaire, l'écorcherie devient donc également un phénomène social qui est à la fois un reflet, une conséquence et un facteur d'aggravation des difficultés des populations.

\footnotetext{
${ }^{100}$ Journal d'un bourgeois de Paris, op. cit., p. 339.

101 En témoignent les anecdotes célèbres à propos de Jeanne d'Arc chassant les prostituées de l'armée : Xavier Hélary, «Prostituées », dans Philippe Contamine, Olivier Bouzy et Xavier Hélary, Jeanne d'Arc. Histoire et dictionnaire, Paris, Robert Laffont, p. 937-938. Sur les problèmes posés par la présence de prostituées dans l'armée anglaise, voir Anne Curry, «Sex and the Soldier in Lancastrian Normandy, 1415-1450 », Reading Medieval Studies, vol. 14, 1988, p. 17-45.

${ }^{102}$ Jean de Stavelot, Chronique, op. cit., p. 432.

${ }^{103}$ Passage cité par Alexandre Tuetey, Les Écorcheurs, op. cit., p. 104. 
En ce qui concerne les gens d'armes, cette conjoncture ne doit pas leur paraître favorable à un abandon des armes et à un retour à la vie civile. En effet, la compagnie est un cadre de solidarité pour des hommes déracinés, ayant parfois passé plusieurs années ou décennies sur les champs de bataille ou dans les tentes et n'ayant donc quasiment plus de relations familiales ou amicales en dehors des armées ${ }^{104}$. L'épidémie mettant à mal les solidarités familiales et amicales, l'écorcherie peut donc apparaître aux yeux de beaucoup comme une solution pour faire face aux difficultés de l'année 1438, que l'hiver approchant ne peut qu'aggraver, et subvenir à leurs besoins par le pillage, le rançonnement et l'appatissement ${ }^{105}$.

La réputation des capitaines d'Écorcheurs dans ces domaines a dû être déterminante: à cette époque, celles de La Hire, de Poton de Xaintrailles, de Rodrigue de Villandrando, des bâtards de Bourbon, de Robert de Flocques ou encore d'Antoine de Chabannes ne sont plus à faire et laissent espérer de substantiels profits. Lors de l'arrivée d'une bande dans une localité, le vol de biens meubles, facilement transportables, échangeables ou vendables, est accompagné du rançonnement de personnes et du bétail : quand Mathelin et Chapelle arrivent avec 700 hommes à Sanvignes au début du mois de novembre 1438, ceux qui ont pu se réfugier dans le château doivent payer une rançon de 300 saluts d'or et tout le bétail dont la rançon n'est pas payée est mis à mort ${ }^{106}$. L'appatissement est également une source de revenus

\footnotetext{
${ }^{104}$ En 1452, Jean Morgent déclare que, après une vie passée au service du roi, son neveu et lui ont tenté de revenir dans leur région natale mais s'y sont retrouvés comme des étrangers, n'y ayant aucun ami :AN, JJ 181, n 3 : Valérie Toureille, « De la guerre au brigandage : les soldats de la guerre de Cent Ans ou l'impossible retour », dans Cahiers du CEHD, vol. 24, Sorties de guerre, dir. Michèle Battesti et Jacques Frémeaux, 2005, p. 34.

${ }^{105}$ L'appatissement est le fait, pour des gens de guerre, de soumettre une localité à un patis : celle-ci est épargnée du pillage en échange d'argent et de vivres.

${ }^{106}$ Marcel Canat, Documents, op. cit., p. 463.
} 
importante: d'après Jean de Stavelot, les clercs de Bâle versent aux Écorcheurs 16000 florins pour prix de leur départ ${ }^{107}$. Parfois, les capitaines monnayent leur protection contre d'autres capitaines, forme d'appatissement déguisé : en octobre 1438, alors même que le roi lui a ordonné d'évacuer les pillards de la région, La Hire est rétribué par la ville de Reims de 520 livres tournois « pour avoir, avec ses gens d'armes, gardé le paiis des grosses routtes et compagnies qui y voulaient entrer ${ }^{108} \gg$. Les recettes de ces exactions sont redistribuées aux hommes d'armes, dont la rémunération est sous la responsabilité du capitaine. Ceux-ci sont ensuite amenés à dépenser leur argent et les non-combattants peuvent espérer voir quelques pièces finir dans leur bourse.

À ces considérations économiques, peut s'ajouter pour les gens de guerre l'accoutumance à un mode de vie caractérisé par l'exercice de la violence, qui ne leur permet pas d'envisager un retour à la vie civile faute d'emploi. Valérie Toureille a montré que de nombreux hommes d'armes qui ont quitté la carrière militaire ont fini par se faire brigands, formant des bandes dont l'organisation ressemble à celle des compagnies ${ }^{109}$. Dans le cas des Écorcheurs, la limite entre hommes d'armes en quête d'emploi et brigands en quête de rapines est floue : ce n'est pas anodin si le terme de brigand vient de la brigandine portée par le soldat, opérant un glissement sémantique de la guerre vers le crime au XIV ${ }^{\mathrm{e}}$ siècle ${ }^{110}$. Pour ces hommes, guerre et brigandage, si tant est qu'ils fassent la distinction, ne sont que les deux facettes de la même activité : dans les deux cas, la violence est exercée comme un gagne-pain.

\footnotetext{
107 Jean de Stavelot, Chronique, éd. Adolphe Borgnet, Bruxelles, Hayez, 1861, p. 432.

${ }^{108}$ Pierre Varin, Archives législatives de la ville de Reims. Collection de pièces inédites pouvant servir à l'histoire des institutions dans l'intérieur de la cité. Seconde partie. Statuts, Paris, Crapelet, t. I, 1844, p. 633.

${ }^{109}$ Valérie Toureille, «De la guerre au brigandage : les soldats de la guerre de Cent Ans ou l'impossible retour », art. cit., et Vol et brigandage au Moyen Âge, Paris, PUF, p. $150-171$.

${ }^{110}$ Ibid., p. 44-46. 
Mais, dans les deux cas aussi, la violence n'est pas qu'un gagne-pain, notamment lorsqu'elle vise des personnes. Partout où les Écorcheurs passent, ce sont les mêmes récits de tortures, de meurtres, de femmes violées et parfois d'enfants mis à mort. En novembre 1438, dans le village bourguignon de Sanvignes, les hommes de Mathelin et Chapelle capturent, en plus des hommes et des animaux, des femmes qu'ils violent. Quelques jours plus tard, dans le village de Saint-Bérain, à côté de Sanvignes, ils tuent un homme et brûlent une femme dans sa maison. Deux autres jeunes femmes sont gardées toute la nuit et libérées le matin suivant contre une rançon : il n'est pas difficile d'imaginer le sort qui leur $a$ été réservé ${ }^{111}$. Le même mois, lorsque Florimont et Saint-Prix viennent avec 300 hommes loger dans le village de Génelard, un valet est capturé, battu et, comme il ne peut pas payer sa rançon, ils attachent de la paille sur son corps et y mettent le feu ${ }^{112}$. L'habitude de la violence va donc parfois jusqu'au plaisir et, même si ce sadisme ne permet pas d'expliquer pourquoi des gens sans emploi restent sous les armes ou sont rejoints par des civils, elle peut constituer une barrière à un retour à la vie civile : Valérie Toureille a montré que des gens de guerre gardent leurs habitudes violentes après avoir quitté le métier des armes ${ }^{113}$.

En ce sens, il ne semble pas qu'il faille faire le lien entre la saison hivernale et l'exacerbation de la violence: si le déficit de nourriture génère sans doute des tensions, des exactions similaires à celles de l'hiver 1438-1439 sont exercées à n'importe quelle saison. André Plaisse a publié un mémoire sur celles commises par Robert de Flocques et Poton de Xaintrailles dans le Rethélois en mai 1445 : partout où ces deux capitaines passent, les villageois sont mis à rançon, battus, torturés, tués ;

\footnotetext{
${ }^{111}$ Marcel Canat, Documents, op. cit., p. 463.

${ }^{112}$ Ibid., p. 467.

113 Valérie Toureille, «De la guerre au brigandage: les soldats de la guerre de Cent Ans ou l'impossible retour », art. cit., p. 35-37.
} 
des femmes sont violées; les églises sont pillées et le bétail est mis à rançon ${ }^{114}$. Dans ce cas, l'hiver et ses difficultés sont bien loin et, selon André Plaisse, la cause de ce déferlement de violences serait le peu d'empressement du gouverneur du Luxembourg à punir ceux qui ont attaqué les hommes de Robert de Flocques ${ }^{115}$. Même si les pillages d'églises et les rançonnements leur donnent une dimension économique, ces exactions montrent, chez les gens de guerre une certaine normalité, voire une norme, de ce qui est perçu par les non-combattants comme des excès de violence.

Dernière explication au caractère extraordinaire de l'écorcherie de l'hiver 1438-1439: la réaction des autorités. Le pouvoir royal tente de circonscrire le phénomène. Le 15 septembre, Charles VII ordonne à Poton de Xaintrailles, Gauthier de Brussac, Rodrigue de Villandrando, Antoine de Chabannes, Florimont, Robert de Flocques, Blanchefort, aux bâtards de Bourbon, de Harcourt, de Vertus, de Culant et de Sorbier de ne pas ravager les terres du duc de Bourgogne ${ }^{116}$. Depuis plusieurs mois, ces capitaines se livrent à des pillages dans le royaume et deviennent une préoccupation pour le roi. Mais les ordres de celui-ci ne font que déplacer le problème ou ne sont pas respectés ${ }^{117}$. Pire, en envoyant ses hommes repousser les Écorcheurs, Charles VII ne fait que grossir leurs rangs : en ordonnant le 29 septembre au bailli de Vermandois, qui n'est autre que La Hire, de nettoyer son bailliage de ces routiers, il favorise l'entrée du

\footnotetext{
${ }^{114}$ Mémoire publié dans André Plaisse, Robert de Flocques, op. cit., p. 253-255.

${ }^{115}$ Ibid., p. 107-108.

${ }^{116}$ Lettre éditée par Marcel Canat, Documents, op. cit., p. 385-387.

117 Le 15 mars 1438, Charles VII défend à Xaintrailles, Brussac et au bâtard de Bourbon de commettre des excès sur les terres bourguignonnes. En avril, il ordonne au bâtard d'Harcourt d'évacuer la Touraine et, en juin, c'est à Robert de Flocques qu'il ordonne d'évacuer la région. Ce dernier obéit... et part ravager la Champagne: Gaston du Fresne de Beaucourt, Histoire de Charles VII, Paris, Société bibliographique, t. III, 1885, p. 394-395.
} 
capitaine et de ses hommes dans l'écorcherie ${ }^{118}$. De même, dans la guerre opposant Antoine de Vaudémont au maréchal de Lorraine, l'emploi de mercenaires favorise l'agglutinement des Écorcheurs dans la région, en même temps qu'il arrange le roi de France, qui les voit enfin s'éloigner de son royaume. Les tentatives du pouvoir royal pour contrôler ces divagations d'hommes d'armes sont complétées par des tentatives de répression. Le 22 décembre 1438, le roi et le connétable de Richemont donnent pouvoir au prévôt de Paris d'arrêter les gens de guerre, posant le principe que «chacun capitaine [...] doit respondre des gens qu'il a et tient en sa compaignie et gouvernement, pour en faire punicion et justice, quant ilz délinquent ${ }^{119}{ }$. Ces mesures judiciaires sont accompagnées d'expéditions punitives menées par le connétable: dans le deuxième semestre de 1438, il est dans la région de Troyes, où il fait prendre, juger et noyer dans la Seine Bouzon de Failles, un capitaine gascon «qui avoit fait des maulx sans nombre ${ }^{120} »$, tandis qu'un capitaine écossais, Bouays Glavy, est pris, jugé et pendu ${ }^{121}$. Cependant, ces mesures sont peu efficaces, le fait que le connétable s'attaque à des capitaines de second ordre montre son incapacité à s'attaquer à des capitaines capables de mobiliser rapidement plusieurs centaines voire plus de mille hommes et peut-être tout simplement une absence de volonté, de la part du roi et du connétable, de se priver du potentiel militaire qu'ils représentent en termes d'effectifs et de talents : tous ces chefs de guerre participent depuis des années, voire souvent depuis plus d'une décennie, à la reconquête du royaume de France. Entre la nécessité de les circonscrire et l'impossibilité

\footnotetext{
${ }^{118}$ Ibid., p. 400.

119 Eugène Cosneau, Le Connétable de Richemont. Artur de Bretagne (1393-1458), Paris, Hachette, 1886, p. 566, qui publie le mandement du connétable. L'ordonnance de Charles VII est publiée dans Ordonnances des rois de France de la troisième race, t. XIII, Paris, Imprimerie royale, 1782, p. 295-296.

120 Guillaume Gruel, Chronique d'Arthur de Richemont, éd. Achille Le Vavasseur, Paris, Renouard, 1890, p. 139.

${ }^{121}$ Ibid., p. 140.
} 
de s'en débarrasser, la marge de manœuvre est étroite.

Ces difficultés se retrouvent à l'échelle du duché de Bourgogne. Pour éloigner les Écorcheurs, le duc, tout aussi impuissant que le roi de France, en vient à employer d'autres hommes d'armes, ce qui, aux dires d'Olivier de La Marche, ne fait qu'empirer la situation :

[...] car à cest occasion fallut que les Bourgoingnons se missent sus [les Écorcheurs], qui tenoient les champs en grant nombre, et vivoient sur le povre peuple en telle derision et oultraige, que le premier mal ne faisoit que empirer par la medecine; et les nommoit on les retondeurs, car ilz retondoient et recourroient tout ce que les premiers avoient failly de happer et de prandre ${ }^{122}$.

Le même phénomène se produit avec les villes qui tentent d'échapper au pillage ou à l'appatissement: elles engagent des troupes pour lutter contre d'autres troupes, à l'image de Reims versant 520 livres tournois à La Hire pour avoir repoussé des routiers. Ainsi, l'écorcherie s'auto-entretient: la présence d'Écorcheurs incite les pouvoirs locaux à engager d'autres hommes d'armes qui, à leur tour, se comportent comme les Écorcheurs et finissent par les rejoindre.

L'exceptionnelle intensité de l'écorcherie durant l'hiver 1438-1439 ne tient donc pas à la saison climatique en elle-même : la plupart des capitaines divaguent déjà depuis plusieurs mois, voire depuis l'hiver précédent, comme Rodrigue de Villandrando. Elle tient plutôt à une conjonction de facteurs qui relèvent à la fois de la situation géopolitique du royaume de France et de ses territoires limitrophes, des difficultés économiques et démographiques de l'année 1438 et de l'incapacité des pouvoirs à limiter l'impact de troupes dont ils ont par ailleurs besoin.

${ }^{122}$ Olivier de La Marche, Mémoires, op. cit., p. 244-245. 


\section{La sortie de l'hiver amène-t-elle une sortie de crise ?}

Pourtant, à la fin de l'hiver, l'écorcherie semble baisser d'intensité. Après leur départ de Bâle, il devient plus difficile de suivre ces compagnies qui, apparemment, se dispersent. Certains capitaines abandonnent leur activité d'écorcheurs, à l'image de La Hire qui, en avril, rentre en France et, en tant que bailli de Vermandois, est présent à Reims le 19 mai pour accueillir avec le connétable de Richemont Catherine de France, la fille du roi, en route pour son mariage avec Charles, comte de Charolais et fils du duc de Bourgogne ${ }^{123}$. D'autres partent exercer leurs talents en dehors du royaume de France : en juin, Rodrigue de Villandrando quitte la région toulousaine et franchit les Pyrénées pour servir le roi Jean II de Castille, qui doit faire face à une fronde de nobles ${ }^{124}$. Cependant, il n'est pas accompagné de toutes ses troupes, dont une partie reste en France et entre sous le commandement de Jean de Salazar, l'un de ses fidèles lieutenants. Quant à Poton de Xaintrailles et Gui de Bourbon, le premier, bailli de Berry, retrouve le service du roi et est nommé capitaine général en Languedoc en 1439, ayant donc pour mission de lutter contre les Écorcheurs ${ }^{125}$; le second tentant de se faire oublier quelques temps à la faveur d'une rumeur sur sa mort ${ }^{126}$.

Le Héraut Berry nous fournit des informations complémentaires sur

\footnotetext{
${ }^{123}$ Francis Rousseau, La Hire de Gascogne, op. cit., p. 324.

${ }^{124}$ Sur cette intervention en Espagne, voir Fernando Castillo Cáceres, « La presencia de mercenarios extranjeros en Castilla durante la primera mitad del siglo xv: la intervención de Rodrigo de Villandrando, Conde de Ribadeo, en 1439 », Espacio, Tiempo y Forma, Serie III, Historia Medieval, t. 9, 1996, p. 11-40. Par la suite, Rodrigue de Villandrando reste en Castille, servant le roi Jean II : José Manuel Calderón Ortega, «La formación del señorío castellano y el mayorazgo de Rodrigo de Villandrando, conde de Ribadeo (1439-1448)», Anuario de Estudios Médievales, vol. 16, 1986, p. 421-447.

${ }^{125} \mathrm{BnF}$, Languedoc bénédictins, 71, fol. 28v. Gustave Dupont-Ferrier, Gallia Regia, ou état des officiers royaux des baillages et des sénéchaussées de 1328 à 1515, Paris, Imprimerie nationale, $\mathrm{t}$. III, 1947, $\mathrm{n}^{\circ} 13802$.

${ }^{126}$ Jules Quicherat, Rodrigue de Villandrando, op. cit., p. 173.
} 
cette baisse d'intensité de l'écorcherie en Bourgogne : «se frappa moult grant mortalité entr'eulx ${ }^{127} »$. Cette baisse d'effectifs a dû avoir pour conséquence un moindre impact du passage des Écorcheurs sur les populations locales, d'autant que certains survivants, qui n'ont pas pu profiter des pillages pour faire face à la disette, semblent en piteux état : lorsque, au printemps 1439, Charles VII se rend dans le Beaujolais, il trouve des routiers «qui estoient plusieurs malades, a pié et desarmez tellement que se estoit grant hydeur de les veoir ${ }^{128} »$. Le chroniqueur ne citant aucun capitaine dans ce passage, on peut penser qu'une sélection s'est opérée à la fin de l'hiver : avant de quitter la région, les capitaines n'ont dû partir qu'avec les hommes les plus aguerris, les mieux équipés et en meilleure santé. Ils ont dû ainsi délaisser les autres, dont sans doute les populations qui ont rejoint les Écorcheurs au cours de leurs pérégrinations, mais qui n'ont ni la force physique ni les compétences nécessaires pour poursuivre les pillages qui leur permettraient de subvenir à leurs besoins ou de se faire employer dans les opérations militaires prévues pour l'été. Cela montre que, malgré les sommes colossales versées pour les patis et les rançons, les Écorcheurs ne peuvent pas tous espérer s'enrichir, d'autant que les effectifs, eux aussi colossaux, ne leur permettent pas de recevoir une part importante lors du partage de ces butins.

D'autres capitaines poursuivent leurs ravages. À la mi-avril 1439, 11000 chevaux sont signalés à Saint-Seine et Vitteaux ${ }^{129}$. Le 10 mai, Antoine de Chabannes attaque et prend le château de Sauturne ${ }^{130}$, dans le

\footnotetext{
${ }^{127}$ Héraut Berry, Les Chroniques de Charles VII, op. cit., p. 198.

${ }^{128}$ Ibid., p. 199. Cela est confirmé par la lettre de la ville de Haguenau du 2 mars 1439 citée par Alexandre Tuetey, Les Écorcheurs, op. cit., p. 104 où il est écrit que les écorcheurs «mangent mal, se contentent souvent de noix et de pain ».

${ }^{129}$ Marcel Canat, Documents, op. cit., p. 390.

${ }^{130}$ Situé dans l'actuelle commune de Saint-Gervais-sur-Couches (département de la Saône-et-Loire), il n'en reste que quelques traces aujourd'hui.
} 
bailliage de Montcenis, tuant, violant, rançonnant les habitants et torturant le seigneur des lieux, dont l'âge avancé ne lui a pas permis de survivre ${ }^{131}$. La fin de l'hiver n'a donc pas amené la fin de l'écorcherie.

Charles VII et le connétable de Richemont tentent, après plus d'une année sans opération d'envergure, de canaliser tout ce potentiel dévastateur lors du siège de Meaux en juillet-août 1439. Philippe Contamine a démontré que les deux tiers des troupes présentes à ce siège se sont livrées à l'écorcherie l'hiver précédent, ce qui représente environ 4000 combattants ${ }^{132}$. Quasiment tous les capitaines d'Écorcheurs participent au siège. Mais les sources mentionnent des pillages collatéraux inhérents à ce type d'opération, certaines troupes étant arrivées sur les lieux plusieurs semaines avant: le Journal d'un bourgeois de Paris signale la présence de pillards dans la région dès le mois de juin ${ }^{133}$; Guillaume Gruel précise que «estoit la pillerie par toute Champaigne et Brie et la Beausse en telle manière que homme n'y povoit mettre remide $^{134} \gg$. Le pouvoir royal a donc besoin de contrôler ces troupes : c'est le sens de l'ordonnance du 2 novembre 1439, par laquelle le roi de France tente de réformer l'armée et de soumettre les gens de guerre ${ }^{135}$. Mais, en raison de la résistance des princes et des grands seigneurs qui y voient une atteinte à leurs prérogatives militaires naturelles, c'est un échec $^{136}$.

Finalement, le cas de l'écorcherie de l'hiver 1438-1439 peut-il

\footnotetext{
${ }^{131}$ Marcel Canat, Documents, op. cit., p. 455-456.

132 Philippe Contamine, Guerre, État et société à la fin du Moyen Âge. Études sur les armées des rois de France, 1337-1494, Paris/La Haye, Mouton, 1972, p. 262-270.

${ }^{133}$ Journal d'un bourgeois de Paris, op. cit., p. 346-347.

134 Guillaume Gruel, Chronique, op. cit., p. 148.

135 Le texte de cette ordonnance est publié par Valérie Bessey, Construire l'armée française. Textes fondateurs des institutions militaires, t. I, De la France des premiers Valois à la fin du règne de François $I^{e r}$, Turnhout, Brepols, 2006, p. 88-101.

136 Eugène Cosneau, Le Connétable de Richemont, op. cit., p. 298-299. Philippe Contamine, Guerre, État et société, op. cit., p. 271-273.
} 
permettre de caractériser cette saison telle qu'elle est vécue par les gens de guerre ? L'intensité exceptionnelle de ce phénomène s'inscrit dans une conjoncture défavorable pour ces routiers : l'absence d'opération militaire importante durant l'année 1438 accentue une précarité inhérente à leur mode de vie et rendue plus difficile par la conjoncture économique et démographique. À cela s'ajoute l'incapacité des pouvoirs à contrôler ces bandes. L'hiver météorologique, caractérisé par le froid, le gel et les précipitations abondantes, a certainement aggravé cette précarité de longue durée mais, celui-ci ne semblant pas anormalement difficile, on ne peut lire et comprendre l'activité des gens de guerre uniquement à l'aune des saisons climatiques. Parler d'hivernement comme le fait Charles VII dans sa lettre du 15 novembre 1438 relève plus du stéréotype que de la réalité : cette notion implique une «interaction dynamique et dialectique de faits sociaux et de faits écologiques ${ }^{137}$ » que les sources ne nous montrent pas dans le cas des Écorcheurs en cet hiver 1438-1439. Pour l'analyse du calendrier de l'activité guerrière, l'expression morte saison est d'ailleurs plus souvent utilisée : comprise comme la période d'inactivité militaire couvrant grosso modo l'automne et l'hiver, avant la reprise des opérations au printemps et à l'été, elle a le mérite de ne pas guider l'analyse en fonction de saisons climatiques aux contours plus nettement délimités. Toutefois, dans le cas des Écorcheurs étudié ici, la «morte saison » dure plus d'un an, de fin 1437 au siège de Meaux qui débute le 20 juillet 1439, interrompue pour une partie d'entre eux par les guerres de Lorraine durant l'hiver 1438-1439. L'activité des gens de guerre n'a donc pas toujours un caractère saisonnier : elle doit être plutôt vue comme une alternance de périodes d'emploi dans les armées, notamment celle du roi de France, seul capable à la fin du Moyen Âge d'organiser des opérations nécessitant des effectifs importants, et de

${ }^{137}$ François Walter, Hiver, op. cit., p. 12. 
périodes de chômage, ces périodes pouvant être de durées très variables. Dans cette perspective, la conjoncture politique, géopolitique mais aussi sociale, économique et démographique est un facteur explicatif essentiel qui invite à ne pas étudier l'hiver des gens de guerre indépendamment des autres saisons, sauf à limiter le champ d'analyse à l'impact des aléas climatiques sur leurs pratiques militaires, mais comme une période s'inscrivant dans une temporalité plus large. 
Carte 1: Itinéraires des principaux capitaines d'Écorcheurs (Conception et réalisation des cartes : Christophe Furon) ${ }^{138}$

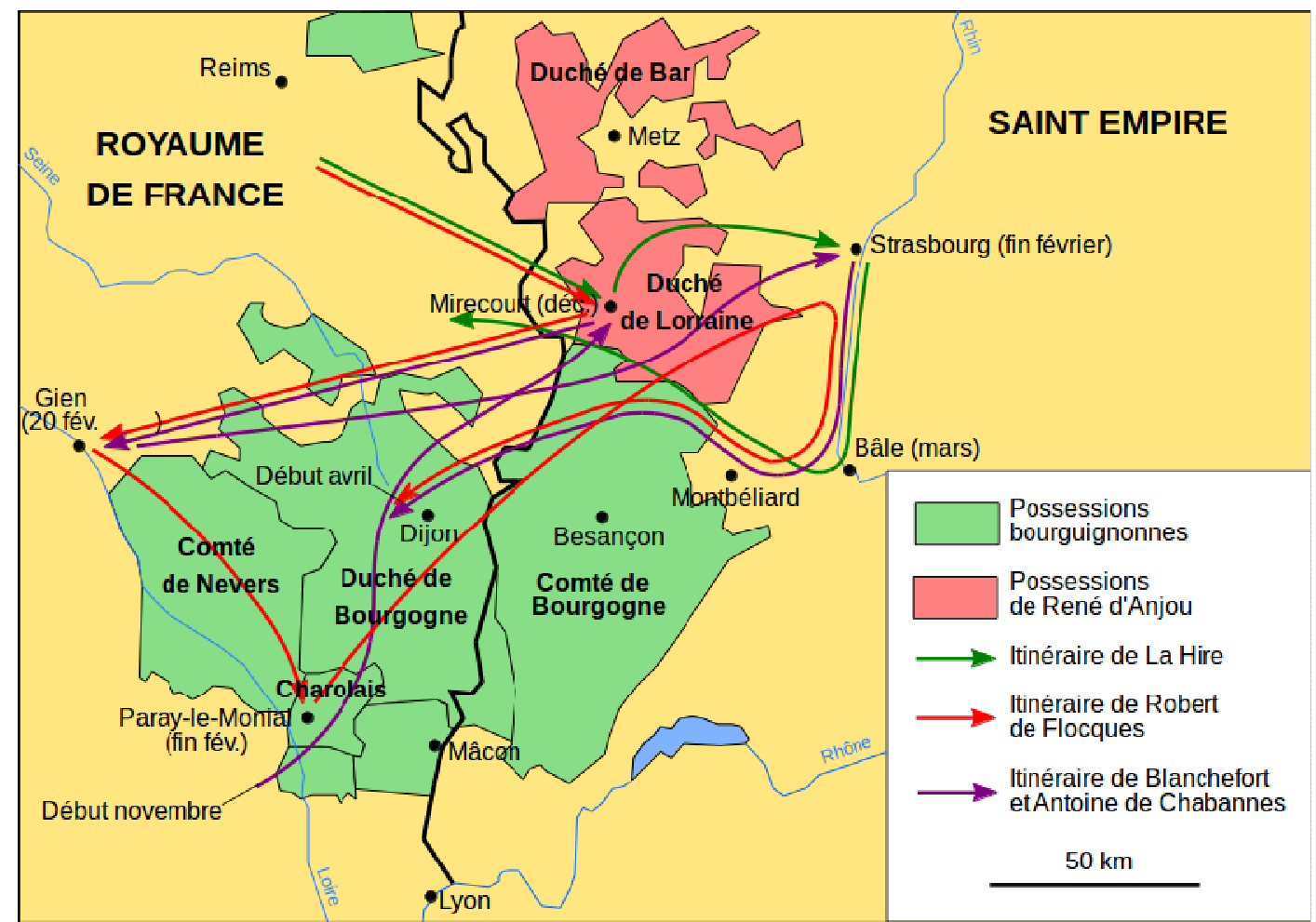

Carte 2: Les Écorcheurs dans le sud du royaume de France (conception et réalisation des cartes : Christophe Furon)

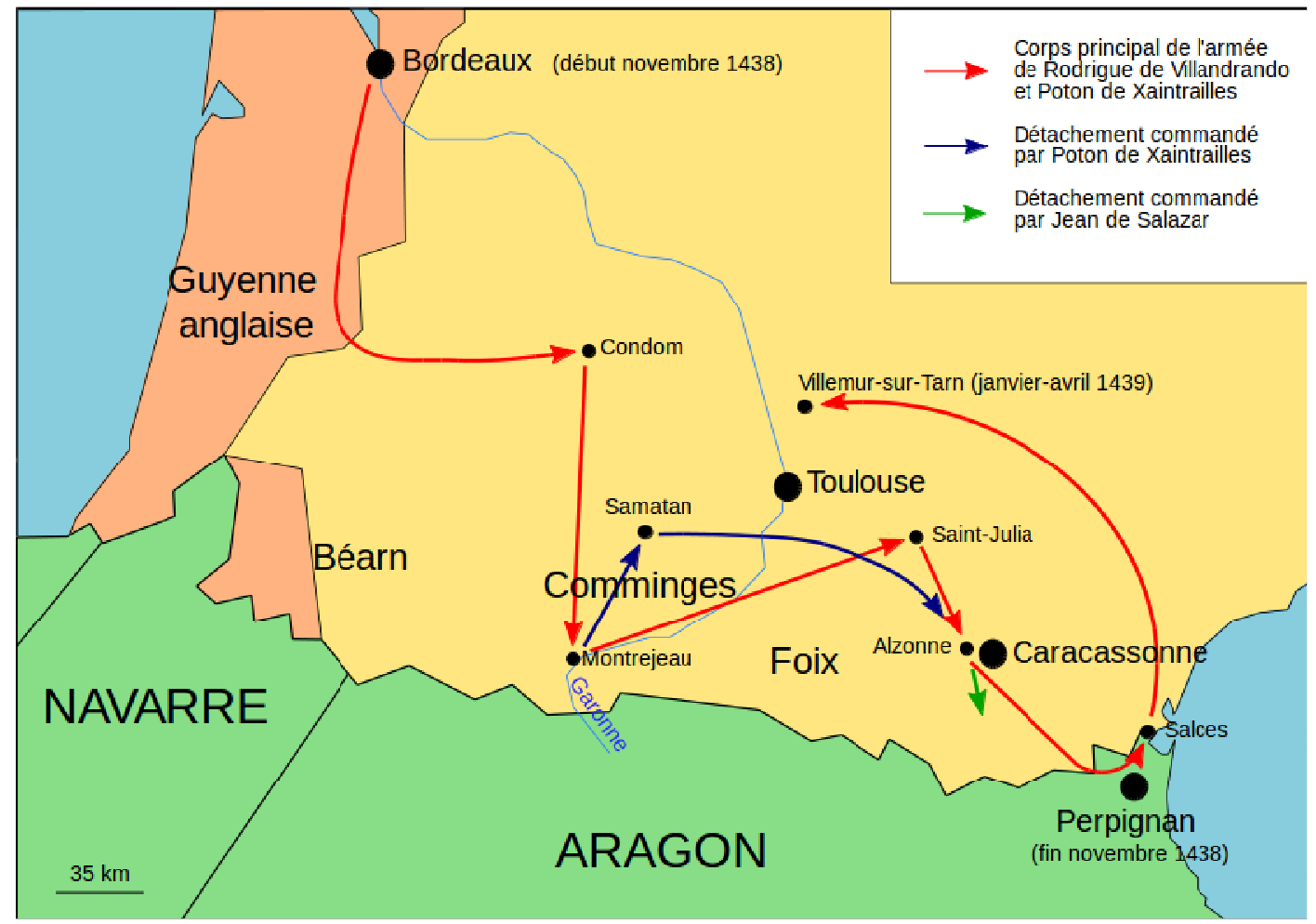

138 Les annexes de cet article peuvent être retrouvées en couleur en ligne sur questes.revues.org. 